\section{REMAR KS}

\author{
on
}

\section{THE STUDY AND PRACTICE OF PUBLIC MEDICINE :}

Being the Introductory Address delivered at the opening of the Winter Session in University College, October $4^{\text {th }}, 1875$.

BY WM. H. CORFIELD, M.A., M.D.(Oxon.), F.R.C.P.(Lond.), Professor of Hygiene and Public Health.

Gentlemen,-In opening the Session here, it is customary for the one who addresses you, either to lay before you an outline of the studies you are going to pursue during your career, and to advise you how best to prosecute them ; or to discuss some topic of especial medical interest at the time ; or to do a little of both. As most of the public lectures given on medical topics of late years have related more or less to sanitary matters, as sanitary questions absorb the greatest amount of interest at the present day, and as not only medical men but all classes of society are interested in them to the highest degree, as they are now made political affairs, and a prime minister comes to us with his famous paraphrase, Sanitas sanitatum, omnia sanitas; and, as the teaching of sanitary science was first started here on a separate footing, and is now being brought into a position of greater prominence, you will hardly be surprised if I consider it my duty as well as my pleasure, to seize this opportunity of attempting to impress upon your minds at the outset of your career, the extreme importance to you as future medical men, on whom will devolve the care of the health of so many others, of a thorough knowledge of the laws which govern the health of individuals and of the community at large, and of the means by which suffering, disease, and death, may be prevented. As you are all probably aware, sanitary science is not yet, like most of the subjects of medical study are, compulsory. Medical students are not obliged to attend lectures on the laws of health; so I want to show you to day how necessary it is for you as future medical practitioners to know something about those laws. Very likely and very naturally, the idea of many of you is that you come here to learn to be medical practitioners, to learn the art of healing, and not to learn how to prevent disease. Indeed, it may seem to you that, by studying to prevent disease, you are studying what is no part of your business. Now, let us consider this for a moment. Medical men study diseases from all points of view. They study how they arise, what their causes are, how they spread, how the pain they cause may be alleviated, and how they may be remedied. Medical men do all this of necessity in order that they may be able to practise their profession. They have to know more about diseases than other people do; they know the conditions of their origin, and how they spread; and they are thereby enabled to point out better than anyone else how they may be prevented. Are they not then bound to do so? Are they not bound (putting away selfish mercenary considerations) to use the knowledge they possess for the good of mankind and to make that knowledge as perfect as possible? Are not the claims of humanity of an importance vastly superior to any others which present themselves under the circumstances? And have not medical men always recognised this? Have they not studied the causes of diseases, and pointed out the ways of preventing them, from time immemorial? Hippocrates was the father of curative medicine-was he not also the father of preventive medicine? Did not Galen and Celsus, and those who followed them, instruct men in the art of preventing disease? Let us come to our own day, and let me call to your minds what our own Sir William Jenner has said on this subject. "To cure disease was the great aim of medicine in the last century. The idea of the vast majority of the public on medical subjects is the popular expression of the views held by the physicians of the generation just gone. The present popular idea of the science and art of medicine is, that it aims chiefly at the discovery of special cures for all special diseases." And further on, "No one acquainted with the present state of the science and art of medicine will for a moment question that to prevent disease is its first and most important aim. That this is the great aim of medicine is a statement made in the opening lectures of all teachers of medicine, and in all their subsequent teachings they never lose sight of the fact." So you will see that Sir William Jenner tells you the first important aim of medicine is to pre- vent disease. Striving to cure comes after failure to prevent, the very fact of the disease being present showing that the means for preventing it have either not been taken or have failed. Or take the words of Sir William Gull, at the meeting of the British Medical Association at Oxford, "It is futile, if not worse, to speak as some do of leaving diseases to work out their own ends, as agents of a moral police. Medicine allows no such prerogative to our judgment. It is enough for us that diseases prevail to stimulate our best efforts for their prevention, without our asking a question beyond."

Now let us consider some of the most remarkable discoveries that have been made by medical men to prevent disease spreading in the world. Who discovered the preventive of small-pox? It was an English medical man-Jenner-who made that discovery. Small-pox was the most terrible and the most fatal epidemic that had ever appeared on the earth. You think, perhaps, that I am exaggerating. Not so. Read the accounts of the small-pox epidemics before the discovery of vaccination. Read of the fearful mortality they caused; equal to one-twelfth of the entire deaths of the whole community, and about one-half the deaths of children under ten years of age. Read of the disfiguration and the blindness caused by small-pox ; to stuch an extent that almost all the population were marked with small-pov, while more than half the total number of cases of blindness were causi $d$ by it. And then you will agree with me that it was the most fear'ul epidemic that ever appeared amongst mankind ; and you will see that, by showing us how to prevent its ravages, Jenner conferred the greatest possible boon on the human race, although he, at the same time, deprived medical men of much practice and of many fees. But who have pointed out the advantages of vaccination? Who have proved by statistics that by it small-pox can be abolished? Who have shown that the longevity of the human race has increased since it has been practised? Who but those the hope of whose gains is gone by its practice? Had medical men only practised vaccination on themselves and their families, they would have been a charmed race among the plague-stricken population, and they would have been able to enrich themselves at the expense of the lives of their fellow-men. They have never done this; but have, in spite of much opposition and much obloquy ; in spite of misrepresentation of the grossest kind, by which ignorant, prejudiced, or interested persons, mislead numbers of their fellow-men-done all in their power to stamp out this terrible dises $\mathrm{s}^{r}$. Compulsory legislation was found necessary on account of the aputhy and ignorance of the people. Compulsory vaccination has been successful to a certain extent, as we do not have anything like the number of deaths from small-pox that we had before its introduction; but why has it not been more successful? Why is so fearful an epidemic as the last one in this country and in France possible? Why but because the dictates of Jenner have not been thoroughly carried out? The reason has been shown by medical men; and it is that revaccination has not been practised, except to a very $: l_{j}, h t$ extent. I believe very few medical men have an idea of the absolute necessity of revaccination for the prevention of small-pox. It has been clearly proved that those who have been vaccinated in tl eir infancy, and again at about the age of puberty, are much less likely to take small-pox than those who have not been revaccinated, or than those who have had it before ; and while the latter, if they do take it, frequently have it much worse than before, and often die of it, revaccinated people almost invariably have it very mildly if at all Out of nearly fifteen thousand cases treated in the metropolitan hospitals during the last epidemic, only four presented evidences of revaccination. We know its effects; but we do not take arlvantage of it to a proper extent. We have compulsory vaccination luws: but I was sorry to see a letter from the Local Government Board which seems to show that they allow the guardians of the poor to exercise their discretion whether or not they shall prosecute a man more than once for neglecting to have his children vaccinated. This is certainly very lamentable. We either have compulsory vaccination here, or we have not. I should like to see a law passed that a child should be vaccinated whether his parents liked it or not. That is what we want ; for an unvaccinated child should no more be allowed to go about among the community than a lion or a tiger. The knowledge which we possess has only been partially applied here. We have nct had a sufficient amount of education on the matter. They have gone further in these matters in Germany than we have. It has been stated, over and over again, by the antivaccinators, that in Germany smallpox epidemics are generally very severe, especially in Prussia, although compulsory vaccination is enforced. I thought that very strange, it true; and I succeeded in obtaining information respecting the statement from official sources at Berlin. I find that small-pox epidemics have been very mild in those states, especially of South Germany, where vaccination was compulsory; but frequent and severe in the kingdom of 
Prussia, with the exception of Hesse Cassel, which has belonged to Prussia since 1866 , and where vaccination has been compulsory. In those parts where vaccination has been compulsory, the deaths from smallpox have been very few. In Bavaria, they were 4 in a thousand; in the Rhenish provinces, 3.7 ; and in Saxony, 8.38 in a thousand, as compared with 16 in a thousand in London, and a percentage of 66.5 in a thousand in Germany, before the vaccination law was passed. In certain of the German states, there had been compulsory vaccination laws; but there had never been such laws in Prussia. The prevalence of small-pox in Prussia, with the marked exception of Hesse Cassel, brought the attention of the legislature to the matter; and, in March of last year (1874), a law was passed making the vaccination of infants and the revaccination of children of riter years compulsory for the whole of the German Empire. Thus Germany has set an example in this respect which other countries would do well to follow; and I doubt inot that they will when they see the spectacle of a great empire in the centre of Europe practically free from small-pox - which will assuredly be the case in $\dot{a}$ few years' time if the law be stringently enforced.

Do all you can, then, to encourage the practice of revaccination; do all you can to spread sound knowledge about it; do all you can to hasten the coming of the day when it will be made compulsory in the British Isles; and you will be benefiting your race, and following in the steps of the great and good man who left to the medical profession the means of abolishing small-pox, and who expected them to carry out those means. If the medical men of all ages had done nothing else, if they had saved no lives, if they had alleviated no pain, if they had prevented no anxiety; if from the time of Hippocrates to the day untill, alas, far distant !) when small-pox shall be as extinct as the dodo, the medical men of all countries had done nothing but fight against that clisease, and had exterminated it, their existence would have been justified, their labour during all those years would not have been lost-it would have been amply rewarded.

But now let us look at some other diseases. Where are the black ceath, the sweating sickness, and the plague? Where is scurvy, that decimator of our armies and navies? They are where typhus fever will soon be, they are where enteric will be some day; they are where every diseave which we conquer, the origin of whose existence we find out, the intricacies of whose paths we unravel, will be sooner or later; they are-practically speaking-abolished. Thanks to the labours of medical men of our own day, of Stewart, of our own Jenner, of Murchison, of Budd, and of many others in less degree, we know now not only the differences between typhus fever and typhoid or enteric fever, long confused, long entered under the same heading in the mortality tables; but we know the different conditions of their existence, the circumstances which favour each, and the ways in which they spread, and what to do to prevent their spread. This is why, I say, we may hope to abolish them. Until we know the special conditions under which a disease flourishes, we can only act on general indications; but when the special conditions are known, we can direct special attention to them.

And what about other infectious fevers, scarlet fever, measles, whooping-cough, and the like? Do we not know more about the ways in which they spread? Have we not come to see that isolation is the one great means to be used? Have we not come to see that special hospitals are necessary, to which patients with infectious fevers should be taken, to separate them from the healthy population? These discases spread from family to family, chiefly by means of day-schools, and children belonging to an infected family, although apparently well themselves, should not beallowed to go to school, as they may carry infection in their clothes. I am sorry to see, from letters in the papers, that the visitors of the London School Board are obliging children who have had these infectious diseases to go to school directly they are considered well; and that they are also compelling children who live in houses where scarlet and other fevers are prevalent to attend school. It is to be hoped that they will soon be taught what they are really doing ; they are spreading disease amongst the people. Another point of great importance, too, is that the clothes from people who have had a disease, or from infected houses, are sent to the wash and infect other clothes; and, in some casts, clothes infected with disease are sent to rag-shops, and the fever is sold with them to one or more customers. You can in these ways do much to prevent the spread of diseases. But you want to know more. You are liable at any time to be called upon to see a case of scarlet-fever or other infectious disease; and you are now expected to advise how to protect others and even how to disinfect premises and things. Your patients will not always allow a sanitary officer to be called in ; but they may expect you to manage everything for them. It would be very desirable if a law were passed compelling all medical men to report every case of infectious disease which comes under their cognisance to the medical officer of health of the locality; and then two ends would be attained: the medical attendant would not run the risk of losing his patients by reporting their houses, and the best means of preventing the spread of the disease would be taken promptly ; for we can do much by isolation, by disinfection, by attention to general and special sanitary conditions, to prevent the spread of those diseases : though natural causes do far more than we can, luckily. I will give you an illustration. The fever case is the type of the epidemic; it has its different periods, its point of maximum intensity, and its decline. Suppose it were not so. Suppose that one man had scarlet-fever in the first week of the year, and gave it to two in the second, and these to two each in the third, and these four to eight others in the fourth, and so on-every person who took it giving it to two the week after, and to no more-a very moderate supposition-I say, if this went on from the first week in January to the end of July, the whole population of the world would have had it; and if it went on for fifty-two weeks, the people who would have had scarlet-fever during the year would people 4,500,000 worlds; and it would take, counting 90 per minute day and night, 100,000,000 of years to count the persons who would have had it. So you see it is very fortunate that there are causes at work in nature to put a limit to the spread of contagious diseases, and that epidemics come to a height before they go on very long. But all medical men are bound to study the methods for the prevention of disease, because the means for prevention are often the same as those for cure. Are not rickets, gout, rheumatism, and many chronic diseases, preventable? And are not the methods for preventing them the same as the means which must be used to prevent their becoming worse? Are not proper diet, pure air and exercise, more effective agents of cure than pharmaceutical preparations? And are you not, therefore, bound to make a special study of these and other hygienic agents ? Remember always the maxim of Rollet of Lyons, "Medicine cures individuals; hygiene saves the masses"; and the dictum of the father of medicine, "Nature is the healer of diseases".

Up to quite recently, the public looked on medicine, as physicians did formerly, thinking that its first duty was to cure, to find a specific remedy for each disease, whether phthisis, cancer, or gout, scarlet fever, typhoid, or cholera. Now, the masses are more enlightened, and require medical men to prekent diseases-or, at least, to prevent them from spreading when they have arisen. A child has scarlet fever in a family-what does its father do? Does he expect the doctor to produce a phial containing a medicine which he will warrant to cure scarlet fever? Not at all. He hopes his child will get well under the doctor's care; but he expects the doctor to know how to prevent others of the family from catching the disease. And the more education is spread, the more will this be so.

But what can we do against our great endemic plagues, with phthisis at their head ; that terrible scourge of our climate which takes from us so many in the prime of life whom we can ill afford to lose? Last year, in London, this one disease caused 8,255 deaths-one-ninth of the total deaths, and more than half as many as all the zymotic diseases. Many circumstances favourable to it have long been known, general unsanitary conditions, hereditary taint, bad food, bad air, certain employments - such as those in which the person is exposed to much dust; but it has been recently shown by Dr. George Buchanan (an old University College man) that the drainage of soil beneath towns reduces the death. rate from it in a most remarkable way-as much as fifty per cent. in one instance-and so knowledge is obtained which enables us to prevent a vast amount of suffering and death from it.

What shall we say of the great infant mortality, mostly from preventable causes? Let us hear again what Sir William Jenner says. " First among preventable diseases I will place one, the mortality from which, in London at least, is so great as beyond question to swell largely the death-rate of children under two years of age; and yet one that has no place in the Registrar-General's returns. I mean rickets, the English disease, as it was formerly called. Not one child ought to die from rickets itself, and death from its consequences ought to be extremely rare ; and yet the mortality from rickets, from diseases which would not occur but for the pre-existing rickets, and from diseases which would be trifling but for the co-existence of rickets is enormous." And, again: "The causes of rickets are : poorness of the mother's blood, errors in diet, i.e., feeding the child with food unsuited to its wants and to its digestive powers, and, as subsidiary causes, deficient light and impure air, produced especially by overcrowding of the sleeping-room. Poverty-inevitable poverty-plays a great part in the pro-
duction of some of these causes." And Sir William Jenner continues : "Judging from my own experience, I should say that rickets so severe as to lead even indirectly to death, would be comparatively rare did the poor know how to feed a young child; were the poor aware of the 
necessity of the infant being fed with food fitted to its age. Law can do something here; for it can make compulsory the teaching of the practical laws of health in all schools supported in any degree by the public money. Diffusion of practical knowledge is the great preventive remedy of rickets."

And now let us hear Dr. Ferguson on the Degeneracy of the Factory Population. In a letter, dated February 26th, 1874, he writes: "Within the last fortnight, six children have come to me, producing registers to prove thirteen, and in one case fourteen years of age. The heaviest of them weighed fifty-six pounds, and the tallest was half an inch over four feet. The average weight of the healthy factory child of thirteen years I find to be seventy pounds, and average height fiftyfour inches." Thus, you see that the heaviest was fourteen pounds under average weight, or one-fifth too light ; and the tallest five and ahalf inches, or about one-tenth too short. He says, too: "I am meeting every week with cases like these, in which feeble children, overtaxed by working full time, either lose weight or grow at a very abnormally slow rate." And : "I am alarmed at the large and increasing number of physically feeble children coming to pass half-time. Many giving proof of nine years come before me, weighing not more than forty-one or forty-two pounds. I am constantly meeting with young persons, aged from fifteen to nineteen years, of not more than the average weight of a healthy factory child of thirteen, whom, when examined for half-time, I noted as physically feeble. For nine years I have closely observed, and am certain that each year the proportion of physically feeble children presented to me has gone on increasing, with the single exception of $1873 . "$

Here is an alarming evil, and one which, if unchecked, will produce a permanent deterioration of the whole factory population. And what are the causes of it? The great cause is the same as the one pointed out by Sir William Jenner as the great cause of rickets-improper and insufficient nourishment. What is the natural nourishment of young children? What is the one perfect food which contains all the necessary substances in proper amount? Milk. Hear Dr. Ferguson again : "From long and careful trial, I find children in the mills to grow, on the average, between thirteen and sixteen years of age, nearly four times as fast on milk morning and night as on either tea or coffee. The exact figures are as four to fifteen. Drinking hot liquids is very destructive to the teeth. Not more than five per cent. of the children I examine have, at the age of thirteen years, sound teeth."

There are other causes, as drunkenness of the parents, and especially of the mothers, by which, of course, money is spent which would buy food ; but the great cause is want of milk.

And how is milk to be got? Why is it so dear? Why is not milk more plentiful? To produce milk in large quantities, we want a great amount of luxuriant grass; and for this rich manure and plenty of water are required ; and have we not got these? We have ; but we do not use them. We deliberately throw them away. Impossible! It is only too true. The rich manure is the sewage of our towns. And now, I fancy, some of you have said to yourselves- "Oh ! Corfield is going to lecture ! It will be all about sewage!" Well, if an apology be necessary, it must be that the utilisation of sewage is the great question of the day, and must not be passed by. The only way to utilise it is to feed plants with it. It is now generally turned into rivers, to render them impure and unfit to drink. The sewage is generally turned into the rivers below the towns, so that the next town below drinks the water into which the sewage from the towns higher up the river has been emptied. In one town, the sewage is actually discharged about a mile above the place from which the town takes out its drinking-water; so that they pollute the water, and then filter and drink it-a most ridiculous circular system. And this is valuable manure that is thrown away. Why, the sewage of London has never been valued at less than one million sterling a-year, and ye that is thrown away, either entirely or almost so. Anything can be grown with it. Grass grows splendidly, especially Italian rye grass; this is the staple sewage crop, and is thoroughly good for cattle food. Cereals can also be produced in abundance with it, as well as vegetables, so that the sewage farmer can grow anything. I have seen oats grown with sewage manure, some ears of which were twenty-seven inches long - plenty of them were two feet long. And, to give you another example, strawberries of most excellent flavour have been grown with sewage, and one of them would not go into an ordinary tumbler. Italian rye grass is very suitable for cattle, and will produce ten cuttings, or eighty tons per acre per annum. Sewage-farms need not be swamps, as some people suppose, and they are not if the drainage be properly attended to. If sewage be passed through the soil, the effluent water is purified at all seasons of the year, even in winter when plant-growth is least. This is the way in which sewage may be made valuable manure, and it is the only way by which the refuse of towns can be turned into food for cattle, and by them to milk, which is required to feed the starving, scrofulous, rickety infants in our great centres of population The solution of the sewage question will afford the means of preventing the degeneracy not only of the factory population, but of the people in large towns generally.

Most of you, I dare say, have heard that several cases have arisen in which epidemics of typhoid fever, and in some instances of scarlet fever, have been traced to infected milk; and $I$ think it is of extreme importance that there should be a Government enactment to have a sanitary inspection of all dairy farms. Remember, too, that we continue to waste our natural resources. A day may come when we shall not be able to get a sufficient supply from elsewhere. We have to rely on supplies from without, which may some day be stopped, and in the meantime we are turning into our rivers and into the sea an immense quantity of manure, and this in spite of the reports of Royal Commissions and Scientific Committees all recommending irrigation as the only remedy. The mention of irrigation leads me to speak of the works carried on now to insure a water-supply. We must hide our heads when we think of the works of the ancient Romans, though carried out by them more as a necessity. Who has not heard of the Roman aqueducts? Water had to be brought from a distance, because they could not raise it in Rome. Some of these aqueducts were forty miles long, and yet the Romans were supplied with three hundred gallons a head per day, while we in London think ourselves well off to get thirty gallons a day. Then the Romans gave us the pattern of our drains. Their great drain was not meant for a sewer, but to drain the ground around the forum, and it does so still. But works are now done more to insure the health of the community, and most of our gigantic works are carried out to this end. Look at the sewerage works in London by which the sewage of from 3 to 4 millions of people is removed continually; all the sewage is thrown away, but that is of less importar.ce. We must first consider how to get rid of it, and, secondly, what to do with it in the way of utilisation. One of the reasons of the low death-rate of London, much lower than that of most large towns, and in parts as low as that of country parishes and small towns, is its excellent drainage. Then medical men are often expected tô understand sanitary architecture, and it is the duty of every medical man to know all the important points connected with the supply of air, with the ventilation of rooms, heating and lighting, and even with the construction of drains and closets to a certain extent; for he is now liable to be asked questions relating to these matters. Every one is taking an interest in sanitary matters, both as regards houses and towns; and medical men, wherever they go, are supposed to be authorities on these things, and their opinion is frequently asked about them; and it is now necessary for medical men to study the broad principles of sanitary science, and, to some extent, the detailed facts, if only to keep up with, and ahead of, the knowledge of other people. If medical men are not to be authorities in matters which relate to the health of the community, who are? It is necessary for all medical men, but more especially for those likely to be charged with the care of the health of the community - to be medical officers of health-to study these matters. Some such appointments have long existed in certain towns, and especially in the metropolis. But by an Act of last sessicn it was provided that all over the country sanitary authorities should be constituted and sanitary officers appointed. We are not to discuss here the constitution of these authorities or their fitness for performing the duties allotted to them by law; sufficient for us to know that strch offices do exist, that there are men appointed all over the country to look after the public health, and that men must be ready to fill up such appointments as they are made or as they fall vacant. No doubt, in time, the appointments will be gradually increased, and the country will be divided into areas, with a superintendent medical officer of health over each, and local medical officers of health in smaller districts under him, and then there will be a much more complete system of supervision than can exist with the haphazard arrangement which we have at present. But be that as it may, the duties of such posts will bc much the same as they are now; and such duties are very manifold, and men must be specially prepared for them. A medical officer of health has to give advice of very various kinds ; he must be conversant with sanitary architecture, and must understand thoroughly all the pipes, traps, etc., which make up the sanitary arrangements of a horrse, and be prepared to advise, where improvements are necessary, what are the best suited to the case. He has, unfortunately, as yet no control over the building of new houses; and another desideratum is one pointed out by Mr. Liddle, and it is that a new Building Act should be passed which shall give the local authorities control in this matter, and make it compulsory that before a new house is allowed to be inhabited, the owner should obtain a certificate or license from the local sanitary authorities, only given after a satisfactory certificate from the 
$\mathrm{m}$ ? lical officer of health and the surveyor. It is true that the medical officer of health has long had power (by Torrens's Act) to report on houses which he considers unfit for human habitation, and that local authorities have had power to pull down or to close such houses, and that now by Mr. Cross's Act, passed last session, power is given to pull down whole areas of houses where they cannot be altered so as to be put in a proper sanitary condition. So far, so good. But we want, as I said, power over new houses. The medical officer of health must also be acquainted with all matters relating to air-surply and ventilation, especially of public buildings - theatres, churches, etc.and with the sanitary arrangements of hospitals, workhouses, asylums, and prisons, which have long since been cleared of the jail fever; and someone has said that they are "the only places fit to live in". He must be prepared to advise in cases of overcrowding, and to give his opinion on all cases of complaints of nuisances of any kind, and to support that opinion by evidence if need be. He must be ac quainted with all the methods for the removal of refuse matters, and know the advantage of each, and the conditions under which it may be applied. His advice is asked on all such important matters as the ventilation of sewers, the treatment of sewage, the cleansing of stree:s, etc., as well as on water-supply and purification. He must be acquainted with the injury to health which is caused by various trades and employments, and with the methods of preventing it, and also with the arrangements for keeping animals in a proper condition, slaughtering cattle and disposing of offal. He must be able to use his microscope, not to mention a number of other instruments of research. He must be acquainted with the ways in which epidemic diseases spread, and with the means to prevent them spreading. It frequently happens in practice that one man gets typhoid fever in a small town, anl, because proper precautions have not been taken, the epidemic spreads all over the town. Another instance may be quoted. A boy comes home with the same disease to a village cottage, the medical man ta'ies proper precautions, and there is not another case of the discase in the village ; whereas, in the same village, before those precautions were taken, an epidemic had several times taken place. Thus there is now room for specialists. One versed in sanitary matters is often now-a-days consulted as to the sanitary condition of a house, especially where cases of fever have occurred. Then the medical officer of health must be a statistician, and, to a certain extent, know how to prepare statistical tables, and to draw correct results from them; and he must be an analytical chemist, too, to a certain extent, though he need not have such an extensive and accurate knowledge as that required by a public analyst ; and he should also be acquainted with sanitary law and with the proceedings of law courts upon such matters.

All these various requirements make it necessary that he should studly many branches of science. As Dr. Guy says, the science of hygiene "makes application of a knowledge remarkable for its amount and the great variety of sources whence it is derived".

And this is why hygiene has only so lately become a science. It is usually defined as the art of preserving the health; the art by which we contrive to lengthen our lives; but it is more than this; it is the science which studies the causes of diseases, and points out the means for the prevention of disease ; for to prevent disease we must study its causes, we must find out the conditions which favour it, which tend to make it spread.

The earliest science is that of numbers, and it is the most perfect: mechanics and astronomy and the other physical sciences are all subject to the science of number, and are all wonderfully perfect because of it. Chemistry - the study of the composition of bodies-is making wonderful advances, but the Newton of chemistry has yet to come. Then biology-the science of life-of which the study of physiology is advancing so much in our day ; pathology-the study of disease-all had to advance to a considerable degree of perfection before hygiene could be born ; it links physiology - the study of healthy action-with pathology, and shows how we pass from health to disease.

The hygienist must be, in the first place, a good pathologist; he must be well acquainted with diseases, and especially with their origin. $\mathrm{He}$ must be a good physiologist and anatomist, for, unless he has made a study of what the normal condition of the human body is, how can he advise as to the methods for keeping it in that condition? He must be a chemist and physicist, and even a mathematician to a certain extent. The more he knows of geology and botany the better, and he must be f.miliar with meteorology. So a hygienist must be a physician; and this is why the universities require men to be B.M.'s before they attempt to take degrees or diplomas in State Medicine. Several of these are now created, and the University of London has established a diploma in this subject; provision has been made for the complete study of it in this College ; and a laboratory is nearly fitted up, in which students will be able to perform for themselves analyses of sam- ples of air, water, and various foods and drinks, and so learn to fulfil the duties required of them as medical officers of health and public analysts.

I hope I have esperially impressed on all the importance of sanitary science to medical men, whether they undertake public duties or not, and that many of you will attend in the summer course on hygiene, if you do not enter for the practical work in the laboratories. Anyhow I wish you all success in your careers, and whatever branch of medicine you take up, remember that it is not only your duty but your privilege to prevent suffering, disease, and death, to the utmost of your power.

You have much to learn; do not put things off. Seize the opportunity. Do not waste your time; every day spent in idleness makes it more difficult to work the next day. On the other hand, beware of neglecting out-of-door exercise, so necessary for the health of the body and of the mind too. You cannot learn well and thoroughly unless you keep your bodies strong; the corpus samum is essential to the ments sana. Do everything earnestly ; be eager in your sports as well as in your work; mind that a few hours of real and genuine hard work are worth days of dawdling, and take as your motto the words of the im. mortal Hippocrates, words so especially applicable to medical studies, "Life is short, but art long; opportunity fleeting; experiment dangerous, and judgment difficult".

\section{MEDICAL REFORMS :}

Biing part of an Address delivered to the Reading Branch of the British Medical Association.

By GEORGE MAY, F.R.C.S., President of the Branch.

The Practice of Midwifery by Women.-The Contagious Diseases .4cts.The Medico-Legal Relations of Insanity.

IT is as President of the Reading Branch of the British Medical Association that I have the honour to address you to-day. It was my privilege to rock its cradle ; I have earnestly watched its progress; and I ask you now to rejoice with me at its distinguished success. In spite of its earlier difficulties, it has become a great institution, an influential power. For the promotion of original researches, and for the in. vestigation of subjects beyond individual enterprise, it extends its fos. tering aid; and for the expression of the opinions and wishes of our profession on questions which demand legislative enactment, it can now speak with an authority which cannot be disregarded. Among many subjects of professional and general interest, there are some which claim especial regard. The education of females to the practice of medicine is one of deep interest and importance. In the promulgation of all that relates to the laws of health, I believe we should find in co-operation with well-educated females a valuable and powtrful help. I should hail the day when the entire department of midwifery were transferred to the charge of competent females. With opportunity to consult with male practitioners in cases of difficulty, $I$ am of opinion that more satisfactory results would follow than by present arrangements. We know how anxious is the position of the practitioner when (detained by an obstetric engagement) he is unable to fulfil his other duties, be they ever so urgent; and we are all too painfully familiar with the difficulties and risks encountered by attendance on infectious cases while engaged in midwifery practice. It were well for the public interests if attendance on both classes of cases conjointly were held to be incompatible ; and I do not see how disassociation could be made practicable, excepting by the substitution of female for male attendants in the entire department of midwifery. The subject is intensely important, and demands at our hands a serious and unselfish consideration.

The Contagious Diseases Act also demands attention from every member of our profession. The enthusiastic and well-meaning, but, I believe, misguided, efforts of numerous opponents of the Act (chiefly on asserted moral grounds) have given the subject more than ordinary interest. The condition of the unfortunate beings obnoxious to this Act is most deplorable. Very many of them are supplied from homes where both sexes and all ages are huddled together, where decency and self-restraint are unknown, and where prostitution would seem to be the natural, if not the inevitable, result. The wonder is not that many have fallen, but that so many have escaped the fall. When overtaken by disease, they are refused admission into many hospitals until evi- 